medRxiv preprint doi: https://doi.org/10.1101/2022.01.27.22269965; this version posted January 29, 2022. The copyright holder for this preprint (which was not certified by peer review) is the author/funder, who has granted medRxiv a license to display the preprint in perpetuity.

It is made available under a CC-BY 4.0 International license .

\title{
Outbreak.info genomic reports: scalable and dynamic surveillance of SARS-CoV-2 variants and mutations
}

Karthik Gangavarapu ${ }^{1, *}$, Alaa Abdel Latif ${ }^{2}$, Julia L. Mullen ${ }^{3}$, Manar Alkuzweny ${ }^{4}$, Emory Hufbauer ${ }^{2}$, Ginger Tsueng $^{3}$, Emily Haag ${ }^{3}$, Mark Zeller ${ }^{2}$, Christine M. Aceves ${ }^{2}$, Karina Zaiets ${ }^{3}$, Marco Cano ${ }^{3}$, Jerry Zhou ${ }^{3}$, Zhongchao Qian $^{3}$, Rachel Sattler ${ }^{5}$, Nathaniel L Matteson ${ }^{2}$, Joshua I. Levy ${ }^{2}$, Marc A. Suchard ${ }^{1,6,7}$, Chunlei $\mathrm{Wu}^{3}$, Andrew I. Su ${ }^{3,8}$, Kristian G. Andersen ${ }^{2,8}$, Laura D. Hughes ${ }^{3, *}$

${ }^{1}$ Department of Human Genetics, David Geffen School of Medicine, University of California Los Angeles, Los Angeles, CA 90095, USA.

${ }^{2}$ Department of Immunology and Microbiology, The Scripps Research Institute, La Jolla, CA 92037, USA.

${ }^{3}$ Department of Integrative, Structural and Computational Biology, The Scripps Research Institute, La Jolla, CA 92037, USA.

${ }^{4}$ Department of Biological Sciences, University of Notre Dame, IN 46556, USA.

${ }^{5}$ Skaggs Graduate School of Biological and Chemical Sciences, The Scripps Research Institute, La Jolla, CA 92037, USA.

${ }^{6}$ Department of Biomathematics, David Geffen School of Medicine, University of California LoS Angeles, Los Angeles, CA 90095, USA

${ }^{7}$ Department of Biostatistics, Fielding School of Public Health, University of California Los Angeles, Los Angeles, CA 90095, USA

${ }^{8}$ Scripps Research Translational Institute, La Jolla, CA 92037, USA.

${ }^{*}$ Corresponding authors

\section{Abstract}

The emergence of SARS-CoV-2 variants has prompted the need for near real-time genomic surveillance to inform public health interventions. In response to this need, the global scientific community, through unprecedented effort, has sequenced over 7 million genomes as of December 2021. The extraordinarily high sampling rate provides a unique opportunity to track the evolution of the virus in near real-time. Here, we present outbreak.info, a platform that can be used to track over 40 million combinations of PANGO lineages and individual mutations, across over 7,000 locations, to provide insights for researchers, public health officials, and the general public. We describe the data pipelines that enable the scalable ingestion and standardization of heterogeneous data on SARS-CoV-2 variants, the server infrastructure that enables the dissemination of the processed data, and the client-side applications that provide intuitive visualizations of the underlying data.

\section{Introduction}

In December 2019, a series of cases of pneumonia of unknown origin appeared in Wuhan, China, and on 7 January 2020, the virus responsible for the diseases was identified as a novel coronavirus, SARS-CoV-2 [1]. The first SARS-CoV-2 genome was made publicly available on 10 January 2020 [2]. Since then, the global scientific community, through an unprecedented effort, has sequenced over 7 million genomes as of December 2021 [3]. To keep track of the evolving genetic diversity of SARS-CoV-2, Rambaut et al. developed a dynamic phylogenyinformed nomenclature (PANGO) to classify SARS-CoV-2 lineages [4]. As of January 2022, over 1,800 lineages have been designated and this has enabled public health agencies such as Public Health England (PHE), the Centers for Disease Control (CDC), and the World Health Organization (WHO) to identify Variants of Concern (VOC), Variants of Interest (VOI/VUI), and Variants Under Monitoring (VUM/VBM) based on the phenotypical characterization of these 
medRxiv preprint doi: https://doi.org/10.1101/2022.01.27.22269965; this version posted January 29, 2022. The copyright holder for this preprint (which was not certified by peer review) is the author/funder, who has granted medRxiv a license to display the preprint in perpetuity.

It is made available under a CC-BY 4.0 International license .

lineages. Currently, there are five designated VOCs: B.1.1.7 (Alpha) lineage resulting in increased transmissibility [5], B.1.351 (Beta) lineage exhibiting immune evasion [6], the P.1 (Gamma) lineage exhibiting immune evasion [7], the B.1.617.2 lineage exhibiting increased transmissibility due to the P681R mutation in the Spike gene [8], and most recently, the B.1.1.529 (Omicron) lineage exhibiting very rapid growth and the ability to substantially avoid antibody neutralization $[9,10]$.

The emergence of SARS-CoV-2 variants has prompted the need for near real-time genomic surveillance to inform public health interventions. In response to this need, thousands of academic, non-academic and public health labs have been depositing sequences on platforms such as GISAID [11]. The extraordinarily high sampling rate provides a unique opportunity to track the evolution of the virus in near real-time. For example, in December 2021, over a million new genomes were submitted to GISAID [12]. Traditionally, phylodynamic approaches have been employed to retrospectively characterize lineage dynamics during outbreaks of viruses such as Zika [13-15], West Nile [16] and Ebola viruses [17,18]. Existing tools like NextStrain [19] and frameworks such as Microreact [20] primarily rely on a phylogeny to elucidate transmission chains and monitor the evolution of the virus. However, these tools were not designed to track thousands of new genomes per day, and given that building phylogenies for large sets of genomes is computationally intensive and time consuming, obtaining timely insights from the data is often problematic [21]. However, the high sampling rate of the virus has opened up the possibility of tracking the pandemic using the available near real-time genomic data without the need for computationally intensive modeling.

Here, we present outbreak.info, a platform that can be used to track over 40 million combinations of PANGO lineages and individual mutations, across over 7,000 locations, to provide insights for researchers, public health officials, and the general public. In the following sections, we describe the data pipelines that enable the scalable ingestion and standardization of heterogeneous data on SARS-CoV-2 variants, the server infrastructure that enables the dissemination of the processed data, and the client-side applications that provide intuitive visualizations of the underlying data.

\section{Results}

The growth rate of a given lineage is a function of epidemiology and its intrinsic biological properties (Figure 1A). For example, the B.1.177 lineage, characterized by an A222V mutation in the spike gene, increased in prevalence in Europe during the summer of 2020 [22]. While initially thought to be more transmissible, it was eventually shown that the increase in prevalence was due to a resurgence in travel and not due to increased transmissibility. In contrast, a few months later the B.1.1.7 lineage was shown to be 40-60\% more transmissible than previously circulating lineages and this intrinsic biological property led to the rapid growth in its prevalence worldwide $[23,24]$. Epidemiological factors such as mobility [25,26], mask usage [27], and public health interventions [28] vary over time and across geographies worldwide while biological properties are a function of the mutations that are found in given lineage (Figure 1A). Hence, to maximize the utility of genomic data for surveillance, we built outbreak.info to enable the exploration of genomic data across three dimensions: geography, time, and lineages/mutations. We use the PANGO nomenclature to estimate the prevalence of SARS-CoV-2 lineages over time and at varying geographic scales. Using a phylogenetically-informed nomenclature allows us to determine genetic features such 
medRxiv preprint doi: https://doi.org/10.1101/2022.01.27.22269965; this version posted January 29, 2022. The copyright holder for this preprint (which was not certified by peer review) is the author/funder, who has granted medRxiv a license to display the preprint in perpetuity.

It is made available under a CC-BY 4.0 International license .

as the "characteristic mutations" of a lineage without directly building a global phylogeny. By not building a global phylogeny, we can update our databases daily using the continuously growing number of SARS-CoV-2 genomes. In addition, we closely track reports from agencies such as the PHE, the CDC and the WHO that designate VOC/VOI/VUMs based on epidemiological analyses. In addition to genomic data, the server also ingests two other types of data: (1) epidemiological data curated by Johns Hopkins University [29], and (2) public literature, clinical trial, protocol, and dataset metadata from sources such as bioRxiv, medRxiv, and LitCovid [30]. Here, we describe how each of these data sources can be used in cohesion to assist in genomic surveillance.

The overall workflow of genomic data is shown in Figure 1B. Genomic data is ingested from the GISAID Initiative, processed via a custom-built data pipeline, Bjorn, and stored on a server which can be accessed via an Application Programming Interface (API). We built two clientside applications, a web interface and an R package which consume this API (Figure 1B). The web interface consists of three main tools focussing on different facets of the underlying genomic data: (1) Lineage and/or Mutation Tracker, (2) Location Tracker, and (3) Lineage Comparison Tool. We designed an opinionated interface for each tool that focuses on one primary dimension of the genomic data with additional customizability of one or more secondary dimensions (Figure 1C). The Lineage and/or Mutation Tracker focus on a specific lineage, mutation or a combination of these. The Location Tracker focuses on a given location and provides a snapshot of currently circulating lineages. Finally, the Lineage Comparison Tool can be used to explore the prevalence of mutations across different lineages. In addition to the web interface, we have built an $\mathrm{R}$ package that authenticates against GISAID credentials and allows programmatic access to the processed data for downstream analyses.

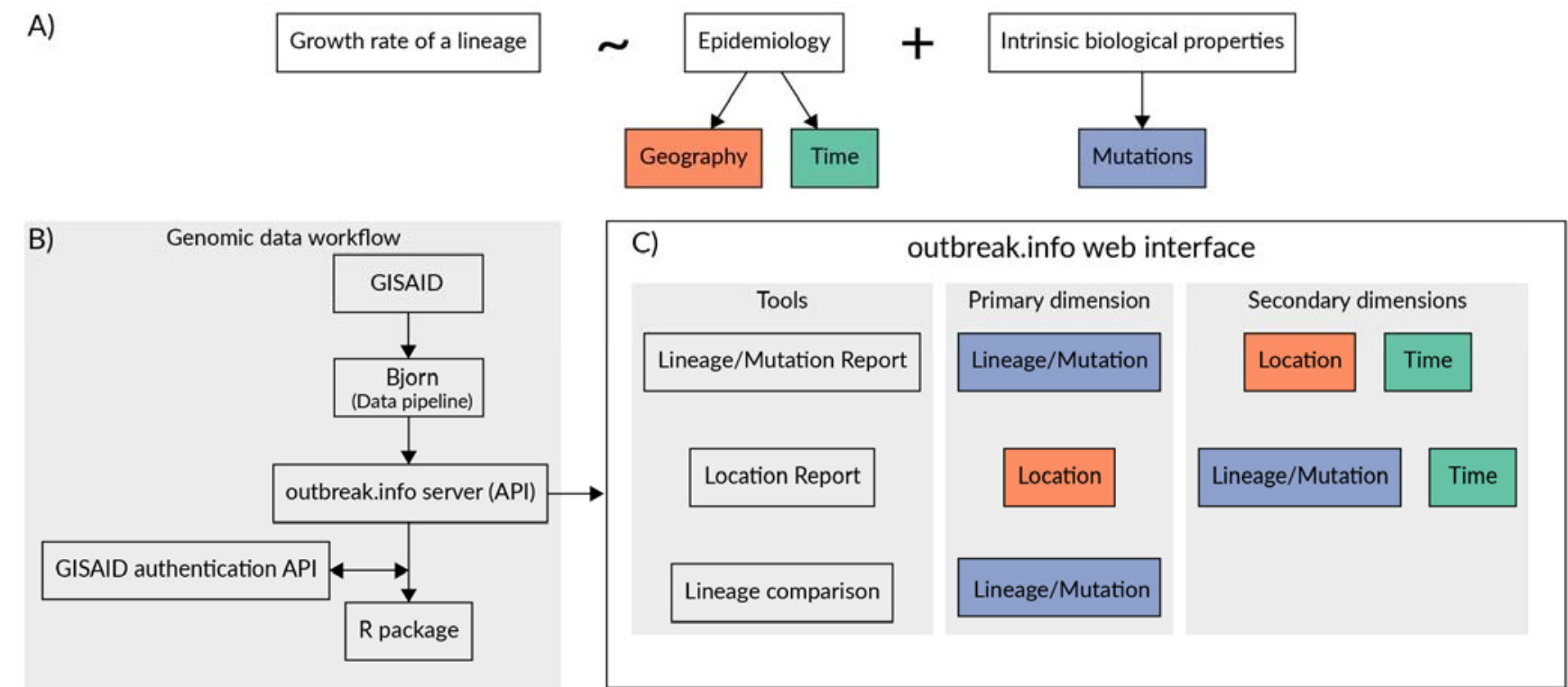

Figure 1. outbreak.info enables the exploration of genomic data across three dimensions. A) Growth rate of a lineage is a function of epidemiology and intrinsic biological properties of a lineage. Further, epidemiology varies over time and by geography while intrinsic biological properties are determined by the mutations present in a given lineage. B) Genomic data is ingested from GISAID, processed using the custom-built data pipeline, Bjorn, and stored on a server which can be accessed via an Application Programming Interface (API). The API is consumed by two clients: A JavaScript based web client and an R package that provides programmatic access by authenticating against GISAID credentials. C) The web interface contains three tools that allow exploration of genomic data across three different dimensions: lineage/mutation, time, and geography. 
medRxiv preprint doi: https://doi.org/10.1101/2022.01.27.22269965; this version posted January 29, 2022. The copyright holder for this preprint (which was not certified by peer review) is the author/funder, who has granted medRxiv a license to display the preprint in perpetuity.

It is made available under a CC-BY 4.0 International license .

\section{Lineage and/or Mutation Tracker}

A fundamental part of genomic surveillance is tracking the growth of a lineage over time. Given the geographic variation in epidemiological, social, and economic factors, it is important to estimate variant prevalence at varying geographic scales. The Lineage/Mutation Tracker can be used to dynamically query the temporal and geographic variation in the prevalence of a (i) VOC/VOI and its sublineages (e.g., Delta and its sublineages), (ii) a lineage (e.g., B.1.1.7), (iii) a lineage and one or more mutations (e.g., B.1.1.7 with S:E484K), (iv) a mutation (e.g., S:E484K), or (iv) a group of mutations (e.g., S:E484K and S:N501Y) (Figure 1A). In addition, users can specify various location scales, such as a country, state, or county (or their local equivalents), to estimate the prevalence of a given lineage and/or mutations. To provide meaningful insights from these prevalence estimates, we designed an opinionated interface to address a specific set of questions listed in Table 1.

\section{Table 1. Questions addressed by the Lineage and/or Mutation Tracker}

\begin{tabular}{|c|c|}
\hline Question & Relevant visual elements \\
\hline $\begin{array}{l}\text { What is the prevalence of a } \\
\text { set of mutations within } \\
\text { different lineages? }\end{array}$ & $\begin{array}{l}\text { Mutations such as S:N501Y, S:DEL69/70, and S:E484K have been shown to } \\
\text { have functional impact on the phenotype exhibited by a lineage such as } \\
\text { increased pathogenicity or immune evasion [31,32]. Furthermore, these } \\
\text { mutations have been acquired independently by many lineages. Convergent } \\
\text { evolution can be used as a metric to assess the importance of any advantage } \\
\text { conferred on a lineage by a mutation. Hence, if a query contains a set of } \\
\text { mutations (e.g., S:E484K and S:N501Y), we estimate the prevalence of that set } \\
\text { of mutations across all lineages globally. (Figure 2B). }\end{array}$ \\
\hline $\begin{array}{l}\text { What is the trend shown by } \\
\text { the prevalence of a lineage } \\
\text { and/or a set of mutations over } \\
\text { time? }\end{array}$ & $\begin{array}{l}\text { Tracking the growth rate of a lineage or a set of mutations over time is very } \\
\text { important to inform public health interventions. We estimate the prevalence of a } \\
\text { given query as a proportion of the total number of sequences collected on a } \\
\text { given day at a given location. To convey the uncertainty in estimating the } \\
\text { prevalence, we calculate binomial proportion confidence intervals using Jeffrey's } \\
\text { interval (Figure } \mathbf{2 C ) .}\end{array}$ \\
\hline $\begin{array}{l}\text { What are the "characteristic } \\
\text { mutations" of a lineage? }\end{array}$ & $\begin{array}{l}\text { The mutations that are characteristic of a lineage can be used to generate } \\
\text { hypotheses about the phenotype exhibited by a lineage based on prior studies } \\
\text { on the functional impact of mutations. We define the "characteristic mutations" } \\
\text { of a lineage as those mutations found in at least } 75 \% \text { of the genomes classified } \\
\text { as the lineage (Figure 2D). These mutations are displayed in a "mutation map" } \\
\text { that can be exported as a TSV file. }\end{array}$ \\
\hline $\begin{array}{l}\text { What is the total number of } \\
\text { sequences that belong to a } \\
\text { lineage and/or a set of } \\
\text { mutations? } \\
\text { In how many countries was a } \\
\text { lineage and/or a set of } \\
\text { mutations detected? } \\
\text { When was this lineage and/or } \\
\text { a set of mutations first } \\
\text { detected? }\end{array}$ & $\begin{array}{l}\text { In order to assess how quickly a variant spread and the extent of the } \\
\text { geographic spread, we show summary of relevant statistics such as the total } \\
\text { number of sequences that match the query, the cumulative prevalence of these } \\
\text { mutations, the first and last date a sequence matching the query was detected } \\
\text { worldwide for a customizable set of locations (Figure } \mathbf{2 E} \text { ). }\end{array}$ \\
\hline
\end{tabular}


What is the geographic prevalence of a lineage and/or a set of mutations?
Many lineages including VOCs Beta and Gamma show a lot of variation in growth rates across different locations. Hence, it is essential to be able to access the geographic distribution of a given lineage. To facilitate this, we show the cumulative prevalence of sequences over the last 60 days across the sub-admin levels of a given location for a lineage/mutation query (Figure 2F). Choropleths are useful visual elements to map geographic variation in prevalence but to further highlight the uncertainty in these estimates and to account for cognitive biases in evaluating locations with different areas, we use a dot chart to show the uncertainty in the point estimate of prevalence over the last 60 days and a bar chart to show the number of sequences used to calculate it (Figure 2G). These two charts can be sorted by the prevalence of the query or the total number of sequences that match the query. This allows the user to account for the effects of sampling bias on prevalence estimates.

What is the latest research available on this lineage and/or set of mutations?
With the growth of new variants over the pandemic, we have seen many studies that focus on important aspects of a lineage such as the ability to evade immune response and the impact on vaccine efficacy. In order to aid in the discoverability of preprints, publications, datasets and other resources, we show the entries that match a given lineage or mutation query from our up-to-date research library [30] (Figure $\mathbf{2 H}$ ). 
medRxiv preprint doi: https://doi.org/10.1101/2022.01.27.22269965; this version posted January 29, 2022. The copyright holder for this preprint (which was not certified by peer review) is the author/funder, who has granted medRxiv a license to display the preprint in perpetuity.

It is made available under a CC-BY 4.0 International license .

A)

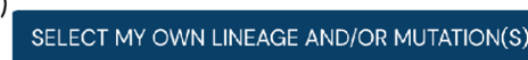

1 Choose variant type

O PANGO lineage

O PANGO lineage + mutation(s)

Mutation(s)

2 Select PANGO lineage

Based on PANGO lineages

Select PANGO lineage

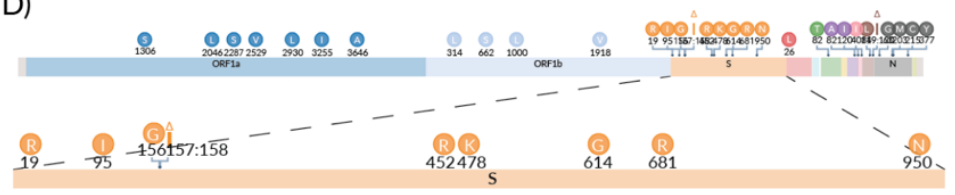

E)

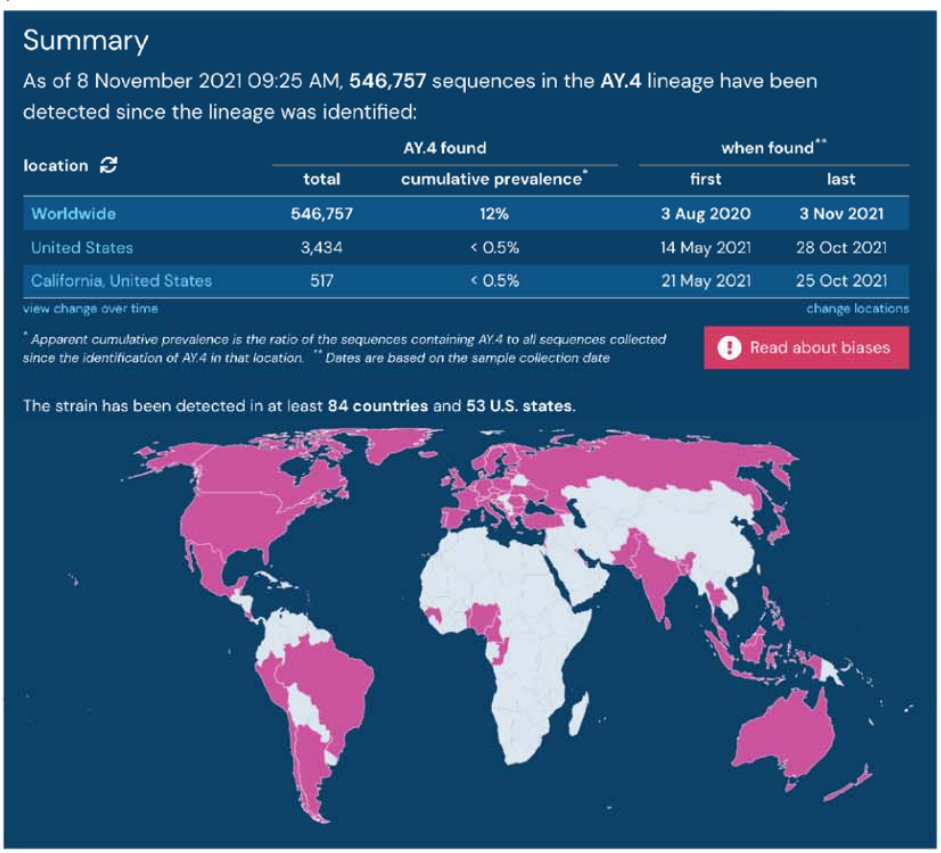

B)
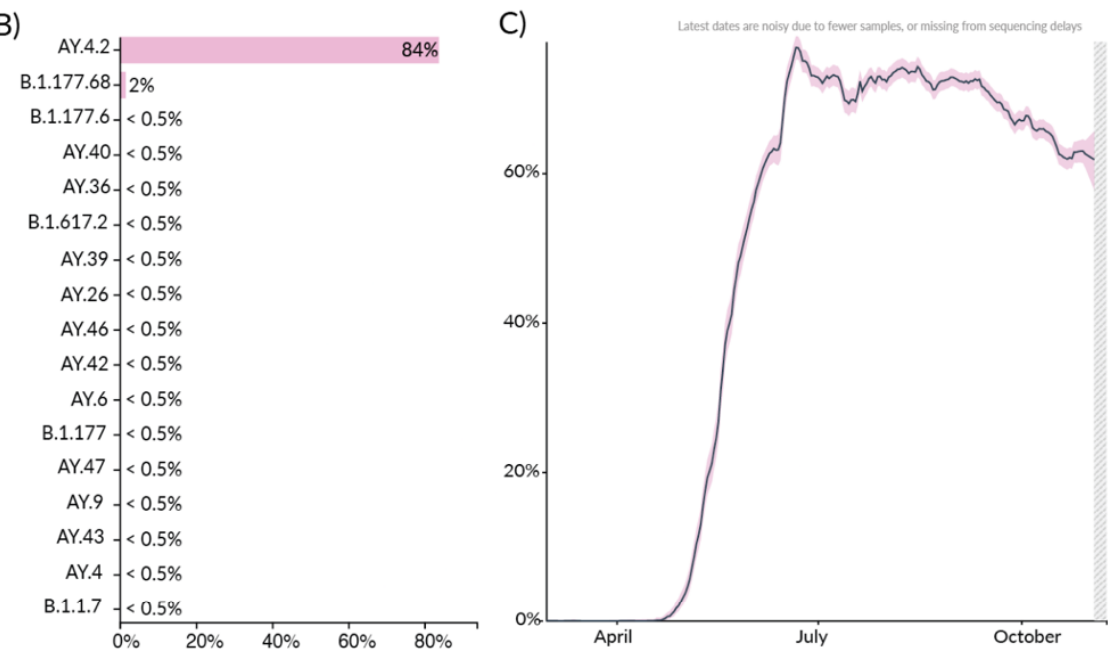

F)
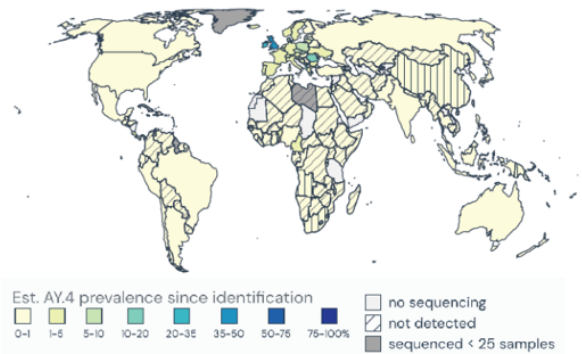

G)

H)

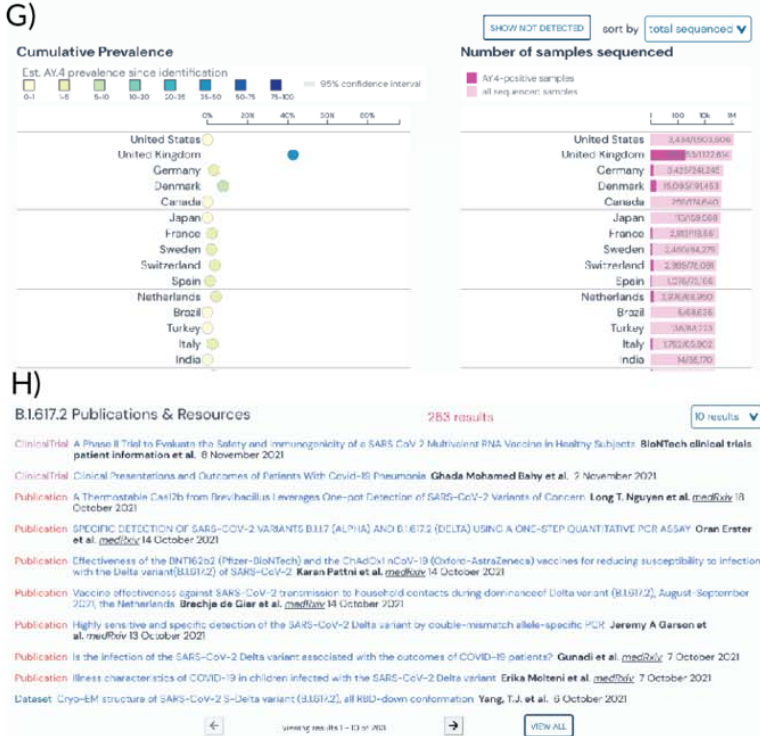

Figure 2. Lineage and/or Mutation Tracker. A) Search and filter options for Lineage/Variant of Concern tracker. B) Prevalence of S:Y145H + S:A222V mutations across different lineages globally. C) Prevalence of AY.4 in the United Kingdom. D) Mutation map showing the characteristic mutations of AY.4. E) Summary statistics of AY.4 lineage. F) Geographic distribution of the cumulative prevalence of AY.4 lineage globally. G) Cumulative prevalence of B.1.1.7 in each country globally. $\mathbf{H}$ ) Research articles, and datasets related to B.1.1.7.

\section{Location Tracker}

Some VOCs have only been regionally dominant. For example, Beta and Gamma were dominant in South Africa [6] and Brazil [33] respectively. Similarly, B.1.621 [34] was only dominant in Columbia, A.2.5 was only dominant in Panama, and B.1.177 exhibited a high growth rate only in European countries due to a resurgence of travel in the summer of 2020 $[22,35]$. Factors such as the attack rate, population immunity due to previous infection or 
medRxiv preprint doi: https://doi.org/10.1101/2022.01.27.22269965; this version posted January 29, 2022. The copyright holder for this preprint (which was not certified by peer review) is the author/funder, who has granted medRxiv a license to display the preprint in perpetuity.

It is made available under a CC-BY 4.0 International license .

vaccination, and social mobility vary from one region to the next and have a significant impact on the growth rates exhibited by a given lineage. To account for such localized factors, it is important to have the ability to track the growth of lineages at different geographic scales. We built the Location Tracker on outbreak.info to facilitate the surveillance of SARS-CoV-2 lineages at a country, state/province, or county/city level. The Location Tracker provides a snapshot of circulating lineages with a focus on the last 60 days, and allows users to compare the prevalence of a customizable set of lineages/mutations over time in that location. Furthermore, the tracker also integrates reported cases over time to provide insights on the impact of growth of various lineages on caseloads in the region. As with the Lineage/Mutation Tracker, we designed the user interface to answer a set of specific questions as shown in Table 2.

\section{Table 2. Questions addressed by the Location Tracker}

\begin{tabular}{|c|c|}
\hline Question & Relevant visual elements \\
\hline $\begin{array}{l}\text { What are the most prevalent } \\
\text { lineages over the last } 60 \text { days? }\end{array}$ & $\begin{array}{l}\text { In order to quickly provide a snapshot of the lineages currently circulating in } \\
\text { a given location, we show a stream graph of the prevalence of lineages over } \\
\text { the last } 60 \text { days (Figure } \mathbf{3 A} \text { ). In order to increase interpretability, we } \\
\text { grouped lineages that are below } 3 \% \text { prevalence for at least five days over } \\
\text { the last } 60 \text { days into a separate category, "Other". The prevalence over time } \\
\text { can be skewed especially in recent days due to the lag between sample } \\
\text { collection, sequencing, and the deposition of sequence data. To convey this } \\
\text { uncertainty, the total number of samples collected are shown in an inverted } \\
\text { bar graph below the stream graph. In addition, a stacked bar graph shows a } \\
\text { snapshot of the cumulative prevalence of the lineages over the last } 60 \text { days } \\
\text { (Figure 3B). Additionally, the user can adjust this window to look at } \\
\text { different time windows, e.g. } 180 \text { days. }\end{array}$ \\
\hline $\begin{array}{l}\text { What is the distribution of } \\
\text { mutations across these } \\
\text { lineages? }\end{array}$ & $\begin{array}{l}\text { The Location Tracker shows a snapshot of currently circulating lineages } \\
\text { which will help identify a newly emerging lineage that exhibits a high relative } \\
\text { growth rate. Often in such cases, the mutations found in the lineage might } \\
\text { provide preliminary evidence on phenotypes exhibited by the virus such as } \\
\text { increased transmissibility or immune evasion. To facilitate this process, we } \\
\text { show the prevalence of mutations that are present in the spike gene of at } \\
\text { least } 75 \% \text { of the sequences of currently circulating lineages (Figure 3C). A } \\
\text { Lineage Comparison Tool is also available which expands upon this } \\
\text { functionality with customizable queries to add lineages based on the name, } \\
\text { VOC/VOI classification, prevalence of mutations, and prevalence within a } \\
\text { location. }\end{array}$ \\
\hline $\begin{array}{l}\text { How does the prevalence of } \\
\text { different lineages or mutations } \\
\text { within this location change over } \\
\text { time? }\end{array}$ & $\begin{array}{l}\text { In addition to showing a snapshot of the lineages circulating over the last } 60 \\
\text { days, we developed a component to show the temporal variation in the } \\
\text { prevalence of a customizable set of lineages/mutations for a given location. } \\
\text { This offers additional flexibility to dynamically select lineages or mutations of } \\
\text { interest and compare their prevalence over time with a customizable time } \\
\text { window (Figure 3D). }\end{array}$ \\
\hline $\begin{array}{l}\text { How does the lineage } \\
\text { prevalence over time } \\
\text { correspond to the number of } \\
\text { daily reported cases in this } \\
\text { region? }\end{array}$ & $\begin{array}{l}\text { The impact of lineage dynamics on the reported cases over time is of } \\
\text { primary concern to public health. To accomplish this, we cross-linked the } \\
\text { reported cases for each location using a standardized location identifier, and } \\
\text { this is shown in a line graph below the prevalence of a lineage (Figure } 3 E \text { ). } \\
\text { In addition, users can select a time range within the prevalence chart or the } \\
\text { reported cases chart to compare trends over a shorter time span. }\end{array}$ \\
\hline
\end{tabular}


medRxiv preprint doi: https://doi.org/10.1101/2022.01.27.22269965; this version posted January 29, 2022. The copyright holder for this preprint (which was not certified by peer review) is the author/funder, who has granted medRxiv a license to display the preprint in perpetuity.

It is made available under a CC-BY 4.0 International license .
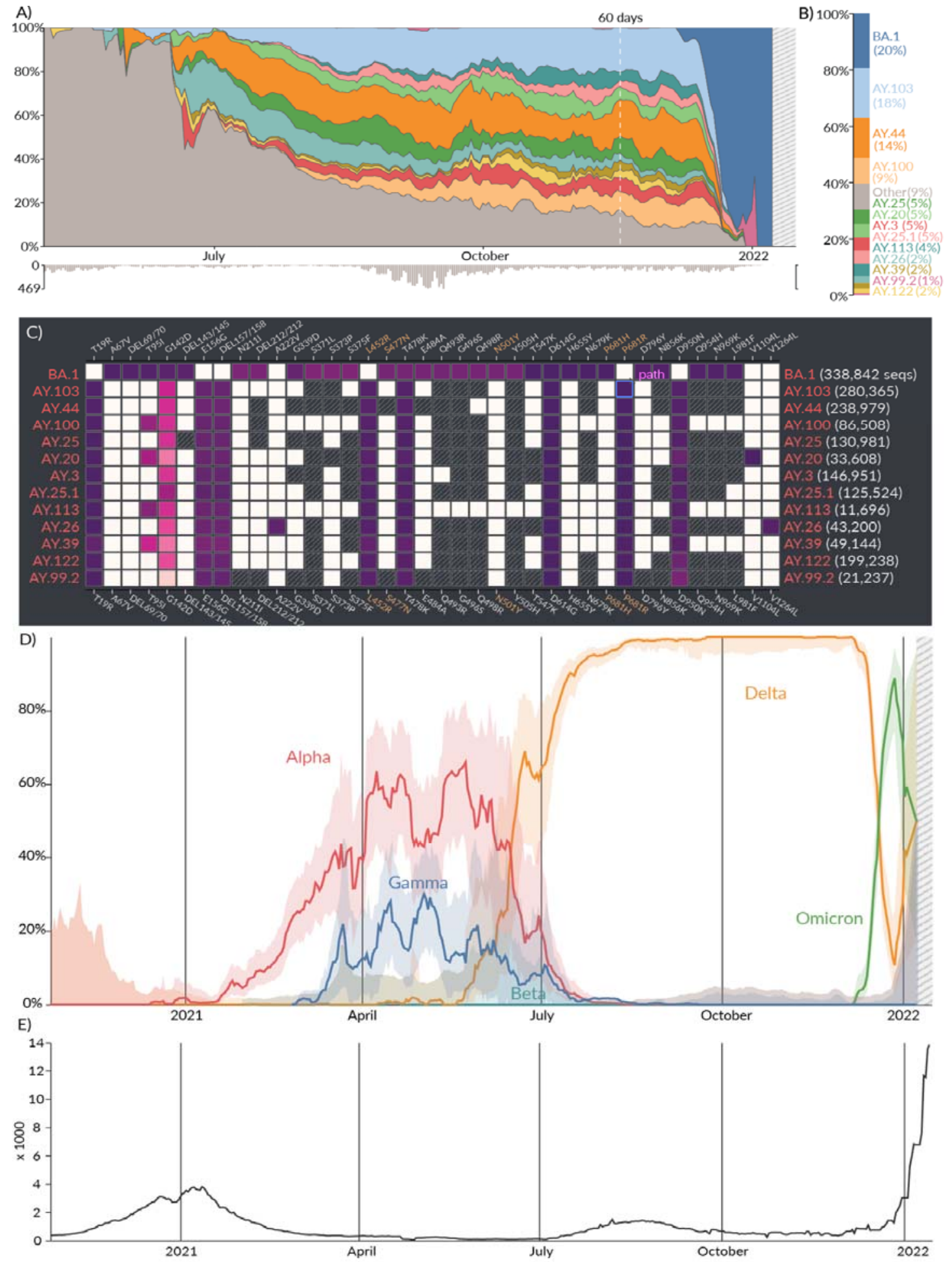

Figure 3. Location report. A) Relative prevalence of all lineages over time in San Diego, California. Total number of sequenced samples collected per day are shown in the bar chart below. B) Relative cumulative prevalence of all lineages over the last 60 days in San Diego. C) Mutation prevalence across the most prevalent lineages in San Diego over the last 60 days. D) Comparison of the prevalence of VOCs grouped by WHO classification: Alpha, Beta, Gamma, and Delta over time in San Diego. E) Daily reported cases in San Diego are shown in the line chart below. 
medRxiv preprint doi: https://doi.org/10.1101/2022.01.27.22269965; this version posted January 29, 2022. The copyright holder for this preprint (which was not certified by peer review) is the author/funder, who has granted medRxiv a license to display the preprint in perpetuity.

It is made available under a CC-BY 4.0 International license .

\section{Case Study: Outbreak.info as a hypothesis generation tool to investigate geographic variation in lineage dynamics of VOCs}

As the pandemic has continued to progress we have seen the emergence of VOCs with significant fitness advantages that were able to outcompete previously circulating lineages. As of January 2022, there have been five designated VOCs: Alpha (B.1.1.7 + sublineages, indicated by $\left.{ }^{*}\right)$, Beta (B.1.351*), Gamma (P.1*), Delta (B.1.617.2*), and Omicron (B.1.1.529*). Of these, Alpha, Beta and Gamma were estimated to have emerged between September and December 2020 [7,36,37] and were subsequently outcompeted globally by the Delta variant that was first detected in December 2020 [38]. The Omicron lineage, first detected in November 2021 [9], was able to outcompete Delta and grew much more rapidly relative to previous VOCs during their emergence (Figure 4A). Whereas Delta and Omicron variants exhibited high growth rates with little variation globally, Alpha continued to circulate in low prevalence in Brazil and South Africa where Gamma and Beta variants were dominant respectively (Figure 4B, 5C). Additionally, there is geographic variation in the prevalence of sublineages within Delta and Omicron variants. The Location Tracker on outbreak.info can be used to track the growth of VOCs within a given location, thus facilitating the comparison of lineage growth rates across locations. The Location Tracker can also be used to track the relative prevalence of sublineages within these VOCS, shedding light on any geographic variation in these dynamics. Here, we examine trends in the prevalence of the five VOCs globally and we highlight the geographic variation in growth rates of Alpha, Beta, Gamma, Delta, and Omicron variants.

The earliest samples of the Alpha variant were sequenced in Southern England in late September 2020 [36]. There were multiple introductions of the lineage into the U.S. as early as late November. The Alpha variant showed a transmission advantage of $40-50 \%$ in the U.S. [24], in line with observations in the United Kingdom and the Netherlands. In the United States, Alpha was able to outcompete previously circulating lineages and continued to increase in prevalence until the introduction of the Delta variant around April 2021 (Figure 4D). In contrast to the U.S., the Alpha variant circulated at very low prevalence in Brazil, while the Gamma variant remained dominant in the country[7] until the introduction of the Delta variant around April 2021 (Figure 4B). Similarly, in South Africa, the Beta variant continued to spread until the emergence of the Delta variant and the Alpha variant never became dominant (Figure 4C). Whereas the Beta and Gamma variants were able to outcompete Alpha in South Africa and Brazil respectively, Gamma only reached a maximum prevalence of $8 \%$ in the U.S. in May 2020, and Beta circulated at a prevalence of $<1 \%$ (Figure 4D). The growth of a lineage is determined by epidemiological factors such as number of introductions, travel between locations, and by intrinsic biological properties such as transmission advantage or immune evasion. Both Beta and Gamma variants show varying degrees of immune evasion [39]. Regions of Brazil had attack rates as high as 75\% in October 2020 [40], indicating that immune evasion was the primary reason for the rapid growth of the P.1 lineage in Brazil. In contrast, states in the U.S. had an estimated attack rate between $0.1 \%$ and $16 \%$ in June 2020 [41]. Given this difference in attack rates, we can hypothesize that the intrinsic transmission advantage of the Alpha variant was able to outcompete the advantage conferred by immune evasion of Gamma in the U.S., but the opposite was true in Brazil and South Africa. In all three countries, the introduction of the Delta lineage displaced previously circulating Alpha, Beta, and/or Gamma lineages in the summer 2021. 
medRxiv preprint doi: https://doi.org/10.1101/2022.01.27.22269965; this version posted January 29, 2022. The copyright holder for this preprint (which was not certified by peer review) is the author/funder, who has granted medRxiv a license to display the preprint in perpetuity. It is made available under a CC-BY 4.0 International license .

The Delta variant of SARS-CoV-2 was first detected in Maharashtra, India in December 2020 [38], has been shown to be $40 \%-60 \%$ more transmissible than Alpha $[42,43]$, and causes a reduction in vaccine efficacy relative to previously circulating lineages [44]. Vaccination campaigns against COVID-19 started in December 2020 and despite the progress of these campaigns [45], the Delta variant continued to cause a renewed surge in infections globally. The Delta variant report, which can be accessed directly on the landing page of the lineage reports view, can be used to understand the dynamics of its sublineages. Figure 4A shows the global prevalence of the Delta variant over time. The growth reflects the transmission advantage that Delta has over previously circulating lineages including VOCs Alpha, Beta, and Gamma. As the Delta variant continued to spread, its genetic diversity increased and as of January 2022, over 200 sublineages of Delta have been designated [46]. Importantly, the prevalence of these sublineages varies geographically. For example, the most prevalent sublineage of Delta in the United Kingdom was AY.4 (Figure 4E) while in the United States most of the transmission was caused by B.1.617.2 (Figure 4F). There was a steady increase in the prevalence of the AY.4.2 lineage in the United Kingdom [47] (Figure 4E) which led to the close monitoring of this lineage until the recently discovered Omicron variant rapidly displaced the Delta variant globally.

The Omicron variant was first detected in November 2021 by genomic surveillance teams in South Africa and Botswana. This variant was associated with a rapid resurgence of infections in Gauteng Province, South Africa and was designated a VOC by the WHO within 3 days of uploading the first genome [9]. The variant grew in prevalence very rapidly and within three weeks, the variant was detected in 87 countries and as of January 2022, Omicron has a prevalence of over $95 \%$ globally (Figure 4A). While increased transmissibility confers a bigger fitness advantage compared to immune evasion when population immunity is low, the opposite is true as population immunity increases either due to vaccination or previous infection [48]. The Omicron variant was found to have a five fold higher chance of reinfection compared to Delta [49] and Omicron infections presented with a higher viral load than wild type but still lower than Delta [50] . As viral load is one of the determinants of transmissibility, this indicates that Omiron is intrinsically not as transmissible as Delta, but it exhibits better immune evasion. This combination gave Omicron a large fitness advantage over Delta as evidenced by its rapid growth rate worldwide (Figure 4A). With the continued spread of the variant, geographic variation in the relative prevalence of its sublineages have emerged. While BA.1 continues to be the dominant sublineage within Omicron globally and in countries such as the United States (Figure 4G), we see the growth of the BA.2 sublineage in Denmark, Singapore, and India (Figure $\mathbf{4 H}, \mathbf{I}, \mathbf{J}$ ). While there are no known phenotypic differences between BA.1 and BA.2, it remains to be seen if BA.2 will continue to grow in relative prevalence within Omicron globally.

This case study illustrates how outbreak.info can be used to not only track and compare the prevalence of lineages across locations but to also derive and support hypotheses regarding the complex interplay between epidemiology and the intrinsic phenotypic characteristics of emerging SARS-CoV-2 lineages as the virus continues to spread. 

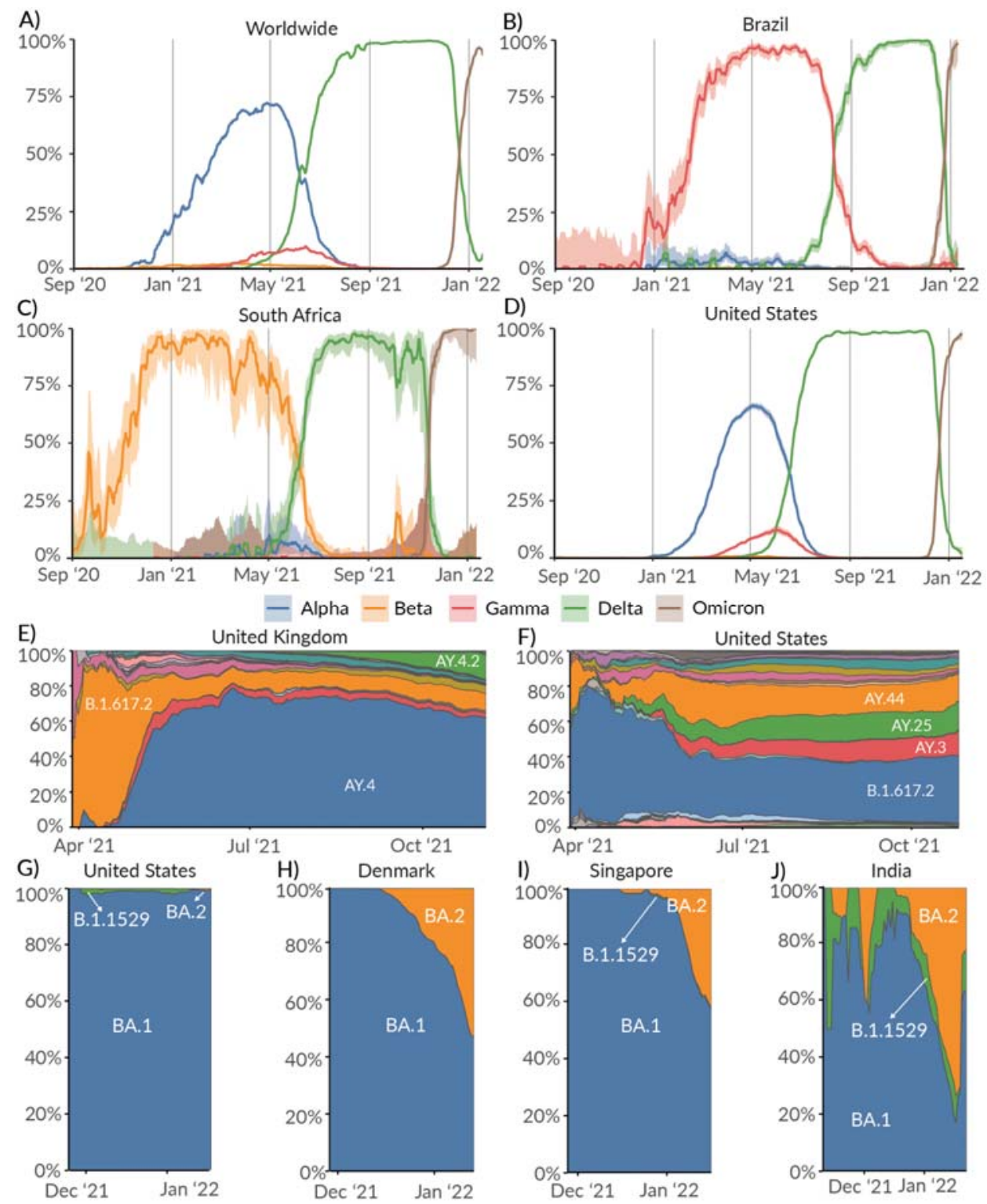

- Alpha
nited Kingdom

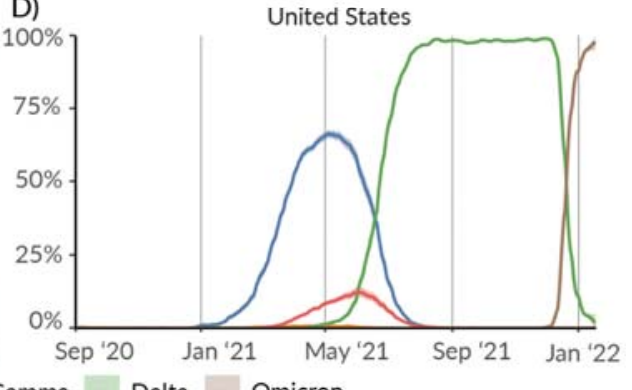

amma - Delta - Omicron

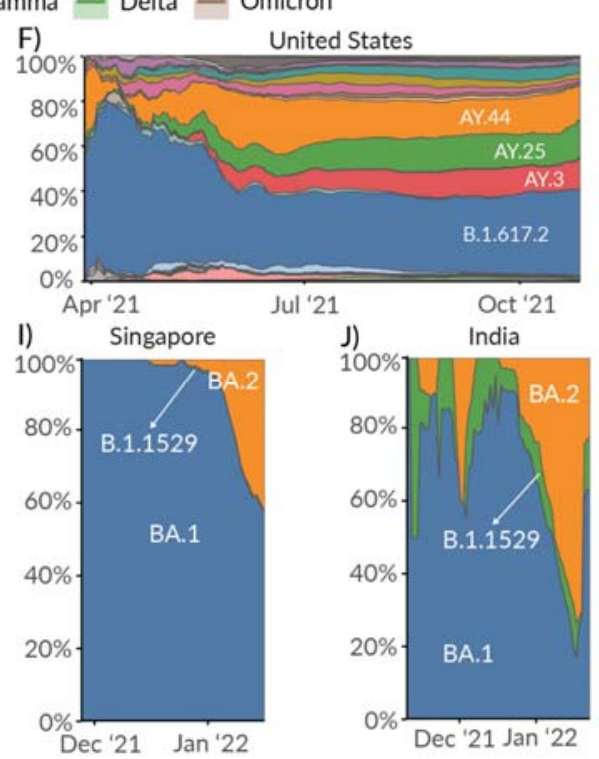

Figure 4. Prevalence of Variants of Concern: Alpha, Beta, Gamma, and Delta lineages over time in the A) Worldwide, B) Brazil, C) South Africa, and D) United States. Relative prevalence of sublineages within Delta variant over time in E) United Kingdom, and F) United States. Relative prevalence of sublineages within the Omicron variant over time in G) United States, H) Denmark, I) Singapore, and J) India.

\section{Discussion}

We developed a platform, outbreak.info, for the continuous monitoring of SARS-CoV-2 variants, based on the integration of three main types of data: genomic data, epidemiological data, and metadata from publicly available resources. For each of these data types, we built pipelines to ingest data from their primary source(s): Bjorn, to ingest genomic data from GISAID [12] via their API feed, EpiData pipeline to ingest epidemiological data from Johns Hopkins University [29], and individual parsers to ingest metadata on published literature, clinical trials, and datasets from many data repositories such as LitCovid [51], bioRxiv [52], medRxiv [53], Protein Data Bank [54], and clinicaltrials.gov [55]. In addition, we use the data pipelines to standardize quantities such as dates, and geographics identifiers, to enable crosslinking data across different sources. 
We designed outbreak.info keeping four goals in mind: Scalability of the application programming interface (API) as existing data sources increase in size and new data sources are incorporated, Interactivity via responsive User interface (UI) elements powered by a high performance API, Interpretability via intuitive visualization of data, and Reusability by providing access to the underlying data through an $\mathrm{R}$ package (Figure 5). To scale with the increasing size of existing data sources and the heterogeneity of newly emerging data sources, we used the BioThings [56] framework that leverages the powerful search capabilities of Elasticsearch [57] Python-based toolkit to easily generate high performance APIs from a number of data sources. We developed customized D3.js [58] visualizations to answer specific questions of interest to epidemiologists, researchers, and public health officials based on user interviews with these audiences followed by iteration guided by usability studies. These visualizations are all interactive and customizable, allowing users to create specific reports for particular locations, variants, and time windows.

Genomic sampling varies globally with the vast majority of sequences coming from high income countries; even within well sampled regions, there is geographic and temporal variation [11]. To communicate the increased uncertainty due to low sampling, we calculate confidence intervals of estimates wherever applicable, provide histograms of sampling density, and mask data when there are very few data points available. Furthermore, sampling can be selective as samples of the Alpha variant and BA.1 lineage (sublineage of Omicron) show $\mathrm{S}$ gene target failure when using a widely used qPCR assay ref. Such sampling biases impact the insights that can be derived from quantities such as the prevalence of a lineage/mutation. We have tried to communicate these limitations through a dedicated "caveats" page with warnings regarding the interpretation of data interspersed throughout the interface. Lastly, to maximize the accessibility of the processed data, we also built an $\mathrm{R}$ package which can be used to authenticate against GISAID credentials and programmatically access the API, enabling researchers to access the data within $\mathrm{R}$ scripts for downstream analyses. 


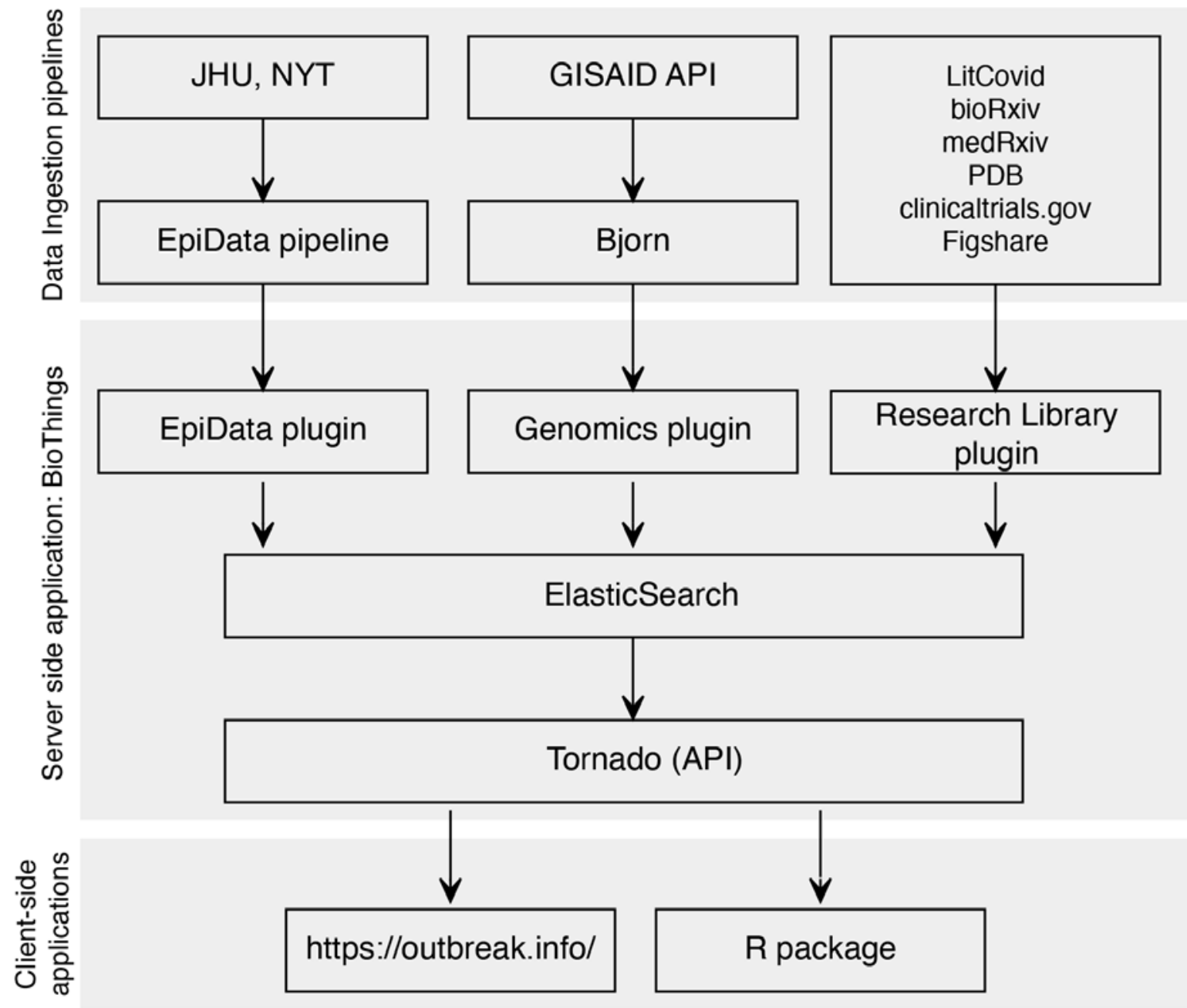

Figure 5. Software infrastructure of outbreak.info. The infrastructure can be broadly divided into (1) Data ingestion pipelines, (2) Server side hosting the database and API server, and (3) Client-side applications that use the API from the server.

\section{Conclusion}

The Omicron variant which was first detected in late November has outcompeted Delta and is currently the most dominant lineage globally. However, it is important to note that regardless of how prevalent previously circulating VOCs were, all five VOCs emerged independent of each other. Hence, continued surveillance of all currently circulating lineages is of utmost importance to public health globally - particularly as SARS-CoV-2 continues to spread and evolve worldwide. We developed outbreak.info as a platform to track the evolving mutational landscape of SARS-CoV-2 at varying temporal and geographic scales. Outbreak.info offers a high degree of customizability, allowing users to interrogate the underlying data to answer specific biological questions and use the platform as a hypothesis generation tool. The user interface has been designed to maximize interpretability by researchers, epidemiologists, and public health officials. The high-performance API in outbreak.info, available through an $\mathrm{R}$ package, increases the accessibility of the underlying data for downstream modeling analyses. The platform has been developed to ensure scalability with growing size of primary data sources and interoperability between different types of primary data, thus, allowing users to track the pandemic comprehensively under a unified framework. 


\section{Methods}

\section{Ingestion of genomic data}

We built a data pipeline, Bjorn, to count mutations from a given set of genomes in a scalable manner daily (Figure 6). The pipeline consists of the following steps: (1) Download SARSCoV-2 genomes from GISAID API; (2) Divide sequences into chunks of 10,000; (3) Align these sequences using minimap2 [59]; (4) Convert the alignment into a FASTA file using gofasta (https://github.com/virus-evolution/gofasta); (5) count mutations and deletions from this alignment; (6) standardize and filter the metadata: country, division, location, pangolin lineage, date of collection, and date of submission and (7) combine results from all chunks and convert to a JSON object. We standardized geographic identifiers using shapefiles from GADM [60]. The final JSON object is loaded into an Elasticsearch index within the BioThings framework [57]. The code for Bjorn is available at https://github.com/andersen-lab/bjorn.
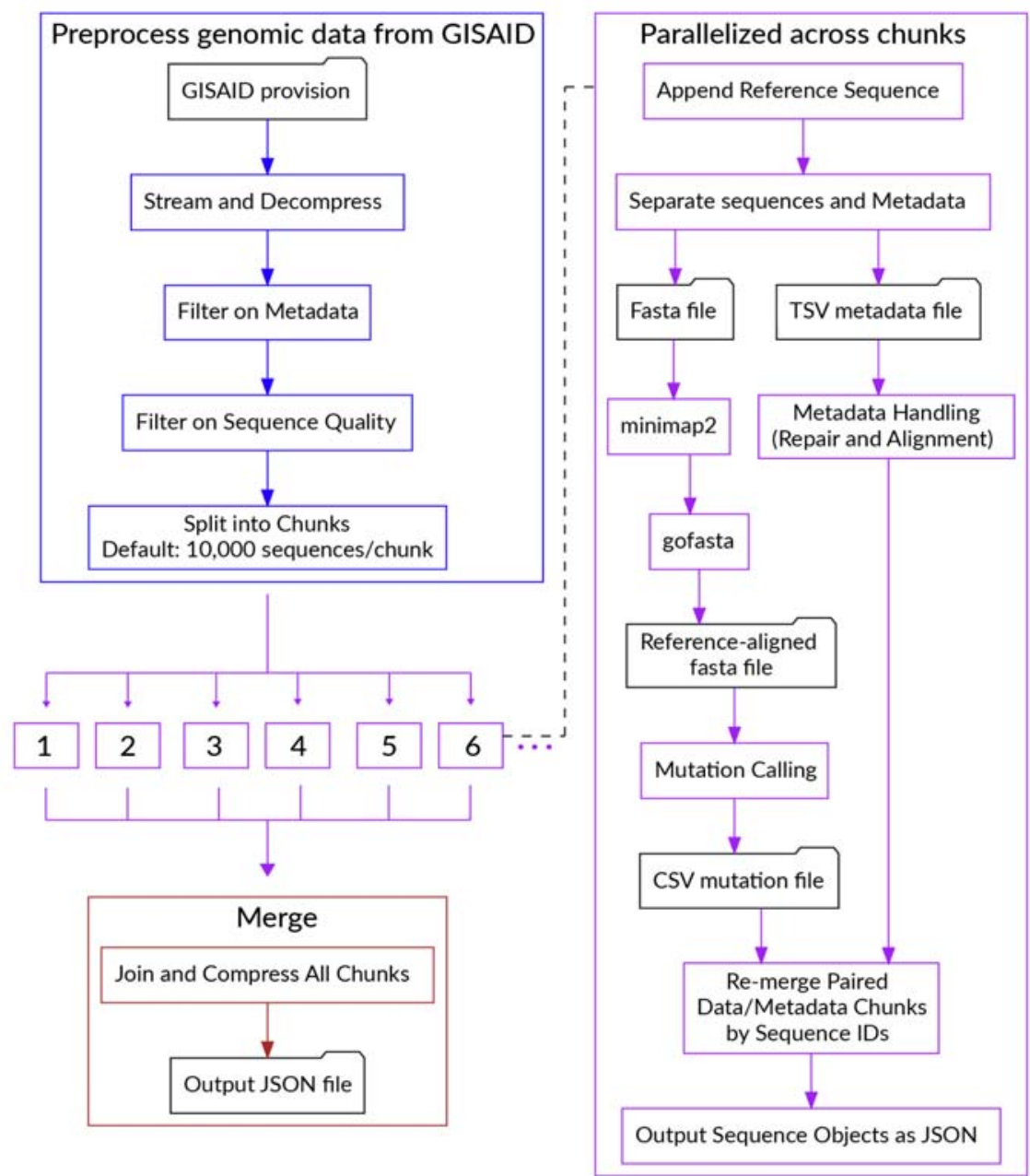

Figure 6. Flowchart describing the steps in Bjorn.

\section{Ingestion of epidemiological data}

We built the EpiData pipeline to ingest reported global cases, and deaths from Johns Hopkins University [29]. We used shapefiles from Natural Earth [61] to standardize geographic identifiers, and obtain populations for countries and states outside the U.S. For the U.S., we used the county level shapefiles and population estimates from the 2019 Census to 
medRxiv preprint doi: https://doi.org/10.1101/2022.01.27.22269965; this version posted January 29, 2022. The copyright holder for this preprint (which was not certified by peer review) is the author/funder, who has granted medRxiv a license to display the preprint in perpetuity.

It is made available under a CC-BY 4.0 International license .

standardize geographic identifiers and get population estimates. We standardized reported date formats, and geographic identifiers across the two resources. The code for the EpiData pipeline is available at https://github.com/outbreak-info/biothings covid19.

\section{Calculation of confidence intervals on prevalence}

Most estimates of prevalence on outbreak.info are binomial proportions. We calculate $95 \%$ confidence intervals for these estimates using Jeffrey's Interval, the 2.5 and 97.5 quantiles of $\beta(\square+0.5, \square-\square+0.5)$ where $\mathrm{x}$ is the number of successes and $\mathrm{n}$ is the number of trials.

\section{Creation of outbreak.info API}

In order to scale with the increasing size of existing data sources and the heterogeneity of newly emerging data sources, we used the BioThings [56] framework [57]. The JSON outputs of our data pipelines are ingested by the BioThings framework and the processed data is stored in individual Elasticsearch indices. A Tornado server is used to create API endpoints that leverage the search capabilities of Elasticsearch to perform complex aggregations of the underlying data. These API endpoints allow the client-side applications to query the underlying data within reasonable query times while accounting for the scale of the ingested data. The BioThings Hub maintains historical data by default, allowing us to roll back to previous data backups if issues are discovered with new data after they are deployed. The code for the server-side application is available at https://github.com/outbreak-info/outbreak.api.

\section{outbreak.info web application}

The web application was built using Vue.js [62], a model-view-viewmodel JavaScript framework which enables the two-way binding of user interface elements and the underlying data allowing the user interface to reflect any changes in underlying data and vice versa. The client-side application uses the high-performance API to interactively perform operations on the database. Customized data visualizations on the client were built using D3.js [58], giving us the ability to develop novel, and intuitive visual elements as part of the user interface. We designed these visualizations to answer specific questions of interest to epidemiologists, researchers, and public health officials. We further added functionality to enable the 1-click copy or download of every chart in the interface as a png or svg. The code for the client-side application is available at https://github.com/outbreak-info/outbreak.info.

\section{R package}

We developed an $\mathrm{R}$ package for outbreak.info to allow researchers and other individuals to easily access the data via the API for downstream analyses and visualizations. The R package is composed of three parts: functions that allow the user to access genomic data, functions to access the epidemiological data, and functions to access the Research Library metadata. They all consist of a base function that contains arguments for all possible parameters that can be used to query the API. While users can utilize this base function directly to access data, several wrapper functions are available that inherit the arguments from the base function in addition to pre-specified parameters to simplify the process of querying the API. For example, while getGenomicData() can be used directly to access data regarding the daily global prevalence of a specified lineage, doing so would require a user to be familiar with the name of the endpoint as specified in the API URL (in this case, global-prevalence). Therefore, these wrapper functions allow users to easily and quickly obtain the data they need. 
medRxiv preprint doi: https://doi.org/10.1101/2022.01.27.22269965; this version posted January 29, 2022. The copyright holder for this preprint (which was not certified by peer review) is the author/funder, who has granted medRxiv a license to display the preprint in perpetuity.

It is made available under a CC-BY 4.0 International license .

In addition, as the API queries location by ISO3 code, rather than by location name, two functions have been created that allow users to forgo the step of searching for the ISO3 code themselves: getISO3Code() and getISO3Code_genomic(). The latter function uses the genomics API endpoint to obtain the ISO3 code for a given location. The ISO3 code can be obtained with either a full or incomplete location name; in the latter case, the user will be provided a list of matching locations and must specify the location they are interested in. This function is embedded in the parent getGenomicData() function, and is therefore inherited in all wrapper functions. Therefore, searching for data by location in the $\mathrm{R}$ package replicates the experience on the client side web application. Documentation is available at https://outbreakinfo.github.io/R-outbreak-info with vignettes located at https://outbreak-info.github.io/Routbreak-info/articles/index.html, and the $\mathrm{R}$ package can be downloaded using the devtools function install_github("outbreak-info/R-outbreak-info").

\section{Acknowledgements}

We thank the technical team, sequence curators, and administrators of the GISAID database for helping us with this project and supporting rapid and transparent sharing of genomic data during the COVID-19 pandemic. We thank our colleagues for sharing genomic data on GISAID. This work was supported by the National Institute for Allergy and Infectious Diseases (5 U19 AI135995-02, 5 U19 Al135995-03S2, 5 U19 Al135995-04S3, R01 Al162611, R01 Al153044), National Center For Advancing Translational Sciences (5 U24 TR002306), and Centers for Disease Control and Prevention (75D30120C09795).

\section{References}

1. Zhu N, Zhang D, Wang W, Li X, Yang B, Song J, et al. A Novel Coronavirus from Patients with Pneumonia in China, 2019. N Engl J Med. 2020;382: 727-733.

2. edward_holmes, arambaut, trvrb, cupton, Kristian_Andersen, kihohong. Novel 2019 coronavirus genome. 11 Jan 2020 [cited 12 Mar 2021]. Available: https://virological.org/t/novel-2019coronavirus-genome/319

3. GISAID - Initiative. [cited 25 Apr 2021]. Available: https://gisaid.org

4. Rambaut A, Holmes EC, OToole Á, Hill V, McCrone JT, Ruis C, et al. A dynamic nomenclature proposal for SARS-CoV-2 lineages to assist genomic epidemiology. Nat Microbiol. 2020;5: 14031407.

5. Davies NG, Abbott S, Barnard RC, Jarvis CI, Kucharski AJ, Munday JD, et al. Estimated transmissibility and impact of SARS-CoV-2 lineage B.1.1.7 in England. Science. 2021. doi:10.1126/science.abg3055

6. Tegally H, Wilkinson E, Giovanetti M, Iranzadeh A, Fonseca V, Giandhari J, et al. Emergence and rapid spread of a new severe acute respiratory syndrome-related coronavirus 2 (SARS-CoV-2) lineage with multiple spike mutations in South Africa. bioRxiv. medRxiv; 2020. 
medRxiv preprint doi: https://doi.org/10.1101/2022.01.27.22269965; this version posted January 29, 2022. The copyright holder for this preprint (which was not certified by peer review) is the author/funder, who has granted medRxiv a license to display the preprint in perpetuity.

It is made available under a CC-BY 4.0 International license .

doi: $10.1101 / 2020.12 .21 .20248640$

7. Faria NR, Mellan TA, Whittaker C, Claro IM, Candido D da S, Mishra S, et al. Genomics and epidemiology of a novel SARS-CoV-2 lineage in Manaus, Brazil. medRxiv. 2021.

doi:10.1101/2021.02.26.21252554

8. Liu Y, Liu J, Johnson BA, Xia H, Ku Z, Schindewolf C, et al. Delta spike P681R mutation enhances SARS-CoV-2 fitness over Alpha variant. bioRxiv. 2021. p. 2021.08.12.456173.

doi: $10.1101 / 2021.08 .12 .456173$

9. Viana R, Moyo S, Amoako DG, Tegally H, Scheepers C, Althaus CL, et al. Rapid epidemic expansion of the SARS-CoV-2 Omicron variant in southern Africa. Nature. 2022 [cited 9 Jan 2022]. doi: $10.1038 / \mathrm{d} 41586-021-03832-5$

10. Liu L, Iketani S, Guo Y, Chan JF-W, Wang M, Liu L, et al. Striking antibody evasion manifested by the Omicron variant of SARS-CoV-2. Nature. 2021 [cited 9 Jan 2022]. doi:10.1038/d41586-02103826-3

11. Brito AF, Semenova E, Dudas G, Hassler GW, Kalinich CC, Kraemer MUG, et al. Global disparities in SARS-CoV-2 genomic surveillance. medRxiv. 2021; 2021.08.21.21262393.

12. Elbe S, Buckland-Merrett G. Data, disease and diplomacy: GISAID's innovative contribution to global health. Global Challenges. 2017. pp. 33-46. doi:10.1002/gch2.1018

13. Faria NR, Quick J, Claro IM, Thézé J, de Jesus JG, Giovanetti M, et al. Establishment and cryptic transmission of Zika virus in Brazil and the Americas. Nature. 2017;546: 406-410.

14. Metsky HC, Matranga CB, Wohl S, Schaffner SF, Freije CA, Winnicki SM, et al. Zika virus evolution and spread in the Americas. Nature. 2017;546: 411-415.

15. Grubaugh ND, Ladner JT, Kraemer MUG, Dudas G, Tan AL, Gangavarapu K, et al. Genomic epidemiology reveals multiple introductions of Zika virus into the United States. Nature. 2017;546: 401-405.

16. Volz EM, Koelle K, Bedford T. Viral Phylodynamics. PLoS Comput Biol. 2013;9. doi:10.1371/journal.pcbi.1002947

17. Park DJ, Dudas G, Wohl S, Goba A, Whitmer SLM, Andersen KG, et al. Ebola Virus Epidemiology, Transmission, and Evolution during Seven Months in Sierra Leone. Cell. 2015;161: 1516-1526.

18. Dudas G, Carvalho LM, Bedford T, Tatem AJ, Baele G, Faria NR, et al. Virus genomes reveal factors that spread and sustained the Ebola epidemic. Nature. 2017;544: 309-315.

19. Hadfield J, Megill C, Bell SM, Huddleston J, Potter B, Callender C, et al. Nextstrain: real-time tracking of pathogen evolution. Bioinformatics. 2018;34: 4121-4123.

20. Argimón S, Abudahab K, Goater RJE, Fedosejev A, Bhai J, Glasner C, et al. Microreact: visualizing and sharing data for genomic epidemiology and phylogeography. Microbial Genomics. 2016;2: e000093.

21. Hodcroft EB, De Maio N, Lanfear R, MacCannell DR, Minh BQ, Schmidt HA, et al. Want to track pandemic variants faster? Fix the bioinformatics bottleneck. Nature. 2021;591: 30-33.

22. Hodcroft EB, Zuber M, Nadeau S, Vaughan TG, Crawford KHD, Althaus CL, et al. Spread of a SARS- 
medRxiv preprint doi: https://doi.org/10.1101/2022.01.27.22269965; this version posted January 29, 2022. The copyright holder for this preprint (which was not certified by peer review) is the author/funder, who has granted medRxiv a license to display the preprint in perpetuity.

It is made available under a CC-BY 4.0 International license .

CoV-2 variant through Europe in the summer of 2020. Nature. 2021;595: 707-712.

23. Volz E, Mishra S, Chand M, Barrett JC, Johnson R, Geidelberg L, et al. Assessing transmissibility of SARS-CoV-2 lineage B.1.1.7 in England. Nature. 2021;593: 266-269.

24. Website. [cited 18 Apr 2021]. doi:10.1016/j.cell.2021.03.052

25. Badr HS, Du H, Marshall M, Dong E, Squire MM, Gardner LM. Association between mobility patterns and COVID-19 transmission in the USA: a mathematical modelling study. Lancet Infect Dis. 2020;20: 1247-1254.

26. Nouvellet $P$, Bhatia $S$, Cori A, Ainslie KEC, Baguelin M, Bhatt $S$, et al. Reduction in mobility and COVID-19 transmission. Nat Commun. 2021;12: 1-9.

27. Fischer CB, Adrien N, Silguero JJ, Hopper JJ, Chowdhury AI, Werler MM. Mask adherence and rate of COVID-19 across the United States. PLoS One. 2021;16: e0249891.

28. Variation in government responses to COVID-19. [cited 7 Nov 2021]. Available: https://www.bsg.ox.ac.uk/research/publications/variation-government-responses-covid-19

29. Dong E, Du H, Gardner L. An interactive web-based dashboard to track COVID-19 in real time. Lancet Infect Dis. 2020. doi:10.1016/S1473-3099(20)30120-1

30. Tsueng G, Mullen J, Alkuzweny M, Cano M, Rush B, Haag E, et al. Outbreak.info: A standardized, searchable platform to discover and explore COVID-19 resources and data. bioRxiv. 2022. p.

2022.01.20.477133. doi:10.1101/2022.01.20.477133

31. Xie X, Liu Y, Liu J, Zhang X, Zou J, Fontes-Garfias CR, et al. Neutralization of SARS-CoV-2 spike $69 / 70$ deletion, E484K and N501Y variants by BNT162b2 vaccine-elicited sera. Nat Med. 2021;27: 620-621.

32. Website. doi:10.1016/j.cell.2020.08.012

33. Faria NR, Morales Claro I, Candido D, Moyses Franco LA, Andrade PS, Coletti TM, et al. Genomic characterisation of an emergent SARS-CoV-2 lineage in Manaus: preliminary findings. virological.org. 2021. Available: https://virological.org/t/genomic-characterisation-of-an-emergentsars-cov-2-lineage-in-manaus-preliminary-findings/586

34. Laiton-Donato K, Franco-Muñoz C, Álvarez-Díaz DA, Ruiz-Moreno HA, Usme-Ciro JA, Prada DA, et al. Characterization of the emerging B.1.621 variant of interest of SARS-CoV-2. Infect Genet Evol. 2021;95: 105038.

35. Lemey P, Ruktanonchai N, Hong SL, Colizza V, Poletto C, Van den Broeck F, et al. Untangling introductions and persistence in COVID-19 resurgence in Europe. Nature. 2021;595: 713-717.

36. O'Toole Á, Hill V, Pybus OG, Watts A, Bogoch II, Khan K, et al. Tracking the international spread of SARS-CoV-2 lineages B.1.1.7 and B.1.351/501Y-V2 with grinch. Wellcome Open Research. 2021;6. doi:10.12688/wellcomeopenres.16661.2

37. Tegally $\mathrm{H}$, Wilkinson $\mathrm{E}$, Giovanetti M, Iranzadeh A, Fonseca V, Giandhari J, et al. Detection of a SARS-CoV-2 variant of concern in South Africa. Nature. 2021. doi:10.1038/s41586-021-03402-9

38. GISAID - hCov19 Variants. [cited 22 Jan 2022]. Available: https://www.gisaid.org/hcov19-variants/ 
medRxiv preprint doi: https://doi.org/10.1101/2022.01.27.22269965; this version posted January 29, 2022. The copyright holder for this preprint (which was not certified by peer review) is the author/funder, who has granted medRxiv a license to display the preprint in perpetuity.

It is made available under a CC-BY 4.0 International license .

39. Hoffmann M, Arora P, Groß R, Seidel A, Hörnich BF, Hahn AS, et al. SARS-CoV-2 variants B.1.351 and P.1 escape from neutralizing antibodies. Cell. 2021;184: 2384.

40. Buss LF, Prete CA, Abrahim CMM, Mendrone A, Salomon T, de Almeida-Neto C, et al. Threequarters attack rate of SARS-CoV-2 in the Brazilian Amazon during a largely unmitigated epidemic. Science. 2021;371. doi:10.1126/science.abe9728

41. Unwin HJT, Mishra S, Bradley VC, Gandy A, Mellan TA, Coupland H, et al. State-level tracking of COVID-19 in the United States. Nat Commun. 2020;11: 1-9.

42. [No title]. [cited 3 Oct 2021]. Available:

https://assets.publishing.service.gov.uk/government/uploads/system/uploads/attachment_data/file /993321/S1267_SPI-M-O_Consensus_Statement.pdf

43. Dhar MS, Marwal R, Radhakrishnan VS, Ponnusamy K, Jolly B, Bhoyar RC, et al. Genomic characterization and Epidemiology of an emerging SARS-CoV-2 variant in Delhi, India. medRxiv. 2021; 2021.06.02.21258076.

44. Mlcochova P, Kemp S, Dhar MS, Papa G, Meng B, Ferreira IATM, et al. SARS-CoV-2 B.1.617.2 Delta variant replication and immune evasion. Nature. 2021; $1-8$.

45. Ritchie $H$, Mathieu E, Rodés-Guirao L, Appel C, Giattino C, Ortiz-Ospina $E$, et al. Coronavirus Pandemic (COVID-19). Our World in Data. 2020 [cited 22 Jan 2022]. Available:

https://ourworldindata.org/coronavirus

46. Cov-Lineages. [cited 25 Jan 2022]. Available: https://cov-lineages.org/lineage_list.html

47. [No title]. [cited 15 Nov 2021]. Available:

https://assets.publishing.service.gov.uk/government/uploads/system/uploads/attachment_data/file /1033101/Technical_Briefing_28_12_Nov_2021.pdf

48. Bushman M, Kahn R, Taylor BP, Lipsitch M, Hanage WP. Population impact of SARS-CoV-2 variants with enhanced transmissibility and/or partial immune escape. Cell. 2021;184: 6229-6242.e18.

49. [No title]. [cited 22 Jan 2022]. Available: https://www.imperial.ac.uk/media/imperialcollege/medicine/mrc-gida/2021-12-16-COVID19-Report-49.pdf

50. [No title]. [cited 25 Jan 2022]. Available:

https://assets.publishing.service.gov.uk/government/uploads/system/uploads/attachment_data/file /1042367/technical_briefing-31-10-december-2021.pdf

51. LitCovid. [cited 29 Apr 2021]. Available: https://www.ncbi.nlm.nih.gov/research/coronavirus/

52. bioRxiv. [cited 29 Apr 2021]. Available: https://www.biorxiv.org/

53. medRxiv. [cited 29 Apr 2021]. Available: https://www.medrxiv.org

54. Bank RPD. RCSB PDB: Homepage. [cited 29 Apr 2021]. Available: https://www.rcsb.org/

55. Home - ClinicalTrials.gov. [cited 29 Apr 2021]. Available: https://clinicaltrials.gov/

56. Xin J, Afrasiabi C, Lelong S, Adesara J, Tsueng G, Su AI, et al. Cross-linking BioThings APIs through JSON-LD to facilitate knowledge exploration. BMC Bioinformatics. 2018;19: 30. 
medRxiv preprint doi: https://doi.org/10.1101/2022.01.27.22269965; this version posted January 29, 2022. The copyright holder for this preprint (which was not certified by peer review) is the author/funder, who has granted medRxiv a license to display the preprint in perpetuity.

It is made available under a CC-BY 4.0 International license .

57. Lelong S, Zhou X, Afrasiabi C, Qian Z, Cano MA, Tsueng G, et al. BioThings SDK: a toolkit for building high-performance data APIs in biomedical research. Bioinformatics. 2022. doi:10.1093/bioinformatics/btac017

58. Bostock M. Data-Driven Documents. [cited 29 Apr 2021]. Available: https://d3js.org/

59. Li H. Minimap2: pairwise alignment for nucleotide sequences. Bioinformatics. 2018;34: 3094-3100.

60. GADM. [cited 29 Apr 2021]. Available: https://gadm.org/

61. Natural Earth - Free vector and raster map data at 1:10m, 1:50m, and 1:110m scales. [cited 29 Apr 2021]. Available: https://www.naturalearthdata.com/

62. Vue.js. [cited 29 Apr 2021]. Available: https://vuejs.org/ 